\title{
Lack of meal intake compensation following nutritional supplements in hospitalised elderly women
}

\author{
Amanda Boudville ${ }^{1}$ and David G. Bruce ${ }^{2 *}$ \\ ${ }^{1}$ Department of Community and Geriatric Medicine, Fremantle Hospital, Fremantle, Western Australia \\ ${ }^{2}$ School of Medicine \& Pharmacology, University of Western Australia, Western Australia \\ (Received 5 May 2004 - Revised 18 October 2004 - Accepted 25 October 2004)
}

\begin{abstract}
Undernutrition contributes to poor clinical outcomes in hospitalised elderly patients but the potential impact of oral nutritional supplements may be reduced by suppressing subsequent food intake. We investigated this possibility in elderly female patients recovering mainly from hip fracture by studying the effect of oral supplements on subsequent food intake during an ad libitum buffet luncheon meal. We tested the effect in seven women by giving the supplement 90 min before the meal and compared energy and macronutrient intake with a control water pre-load condition. A similar study was carried out in another seven women with the supplement or water drink given $30 \mathrm{~min}$ beforehand. Both self-rated appetite and energy intake were low in these women. The nutritional supplement did not alter ratings of hunger, fullness or prospective consumption or subsequent energy and macronutrient consumption whether given 90 or 30 min before the meal. There were significant independent correlations between the lack of adequate compensation of energy intake at meals and chronic undernutrition (as assessed by skinfold thickness) and energy intake during the control meal. We conclude that elderly women during the recovery phase after major fractures have low appetites and energy intakes and markedly impaired adjustment of energy intake following liquid oral nutritional supplements. The reasons for this are unknown but are related to anorexia and undernutrition. The consumption of liquid oral supplements given up to 30 min before a meal does not suppress subsequent energy intake from meals.
\end{abstract}

Older women: Inpatient care: Oral supplements: Meal intake compensation

Nutritional surveys have shown that undernutrition is common in hospitalised elderly patients (Sullivan et al. 1995). This occurs on a background of decreased energy intake seen in older people probably due to a combination of physiological, patho-physiological and psycho-social changes that cause a reduced appetite (Morley, 1997). Elderly patients hospitalised with hip fractures are often malnourished at the time of the fracture (Bastow et al. 1983) and many have suboptimal intakes during the recovery phase (Stableforth, 1986; Jallut et al. 1990) that lead to further weight loss (Bruce et al. 2003) and adverse clinical outcomes (Bastow et al. 1983; Sullivan et al. 1995). Recent reviews of the use of oral nutritional supplements to combat low energy intakes during hospital stays have concluded that their use may be beneficial on mortality rates and rehabilitation outcomes, but that available evidence is weak (Potter et al. 1998; Avenell \& Handoll, 2001). Nevertheless, the use of liquid oral supplements has been widely adopted, in part stimulated by possible cost savings for hospitals (Tucker \& Miguel, 1996).

Not all trials have demonstrated benefit from oral supplements (Potter et al. 1998; Avenell \& Handoll, 2001), possibly because poor compliance with oral supplements occurs due to anorexia (Avenell \& Handoll, 2001; Bruce et al. 2003). Anorexia in older hospitalised patients may be multifactorial in origin, related to medications, the inflammatory response, inactivity, sarcopaenia and a number of peripheral or central regulatory systems (Morley, 1997). One potential problem that has been little studied in these patients is the impact of oral nutritional supplements on subsequent food intake. When healthy young adults are given 'pre-meals', subsequent food intake is reduced and total energy intake is balanced. This energy compensation is remarkably precise in young men and in older people has been reported to be normal (Zandstra et al. 2000) or mildly impaired (Rolls et al. 1995). A recent study found a severe lack of compensation of energy intake after pre-meals in profoundly malnourished elderly women (Sturm et al. 2003). In contrast to this latter study, there is anecdotal and research evidence that suggests that prescribing oral supplements to undernourished elderly subjects may not always be beneficial because they may suppress subsequent food intake (Banerjee et al. 1978; Fiatarone et al. 1994; Kayser-Jones et al. 1998). In two controlled studies, no net increase in total energy intake was seen in nursing home residents given oral supplements because they reduced the amount of food eaten during meals (Banerjee et al. 1978; Fiatarone et al. 1994). We have utilised a pre-meal study design to examine the impact of a standard oral nutritional supplement on subsequent food intake in a group of elderly hospitalised patients.

\footnotetext{
Abbreviations: AMA, arm muscle area; CAMA, corrected arm muscle area; SGA, Subjective Global Assessment.

* Corresponding author: Associate Professor David G. Bruce, School of Medicine \& Pharmacology, Fremantle Hospital, P.O. Box 480, Fremantle, Western Australia 6959, Australia, fax +6161894313229, email dbruce@cyllene.uwa.edu.au
} 


\section{Subjects and methods}

\section{Subjects}

A convenience sample of fourteen consecutive women with recent osteoporotic fracture were recruited from the geriatric rehabilitation ward at Fremantle Hospital. All were in the rehabilitation phase of recovery after having been admitted to hospital with an osteoporotic fracture (i.e. following a simple fall) then transferred to the rehabilitation ward for further management. Of the fourteen, thirteen had a hip fracture and had undergone surgical repair and one had sustained a pelvic fracture. All had been in hospital for at least $14 \mathrm{~d}$ and none had dysphagia or feeding problems related to dentition or other conditions or a history of recent pre-fracture weight loss. None was suffering from postoperative complications or acute illness at the time of study and other exclusion criteria were alcohol abuse, significant gastrointestinal symptoms, previous gastrointestinal surgery, active malignancy, diabetes mellitus, depression (score $>7$ on the BASDEC depression screen; McCrea et al. 1994), severe cognitive impairment (score $<20$ on Mini-mental State Examination), or the use of drugs known to affect appetite (e.g. antidepressants, opiates). Most had other conditions such as hypertension, coronary artery disease or arthritis and most were regularly taking other medications for them. None of the subjects had evidence of high dietary restraint or eating abnormalities (Garner \& Garfinkel, 1979; Stunkard \& Messick, 1985). All subjects gave informed consent and the study was approved by the Fremantle Hospital Research and Ethics Committee.

\section{Procedure}

The study had a within-subject design with each subject acting as her own control. Each subject was studied on two occasions within $2-3 \mathrm{~d}$ in random order. The meal procedure and nutrient calculations were carried out by a trained research dietitian. All study sessions were conducted in a social room adjoining the rehabilitation ward. All subjects were allowed a standardised light breakfast meal before 08.00 hours (tea, one or two slices of toasted bread, butter), then they were required to fast until the study procedure. They were taken to the study room and allowed to settle themselves before the procedure commenced at 11.30 hours. They were required to drink either a nutritional supplement drink or an equal volume of water $(250 \mathrm{ml})$ within $10 \mathrm{~min}$ and all succeeded in this requirement. They then waited before being offered a standard, buffet-style meal. This was prepared in excess of what would normally be eaten by an adult and they were invited to eat as they wished. In study A, seven subjects were given the buffet meal $90 \mathrm{~min}$ after the pre-meal drink. A delay of $90 \mathrm{~min}$ was used as this corresponds to other premeal studies (Zandstra et al. 2000; Sturm et al. 2003) and has been recommended for clinical use in nursing homes (Wilson et al. 2002). A subsequent seven subjects underwent the identical procedure except that the meals were provided $30 \mathrm{~min}$ after the pre-meal drink (study B). A 30 min time delay is recommended as the most effective time to demonstrate energy compensation (Rolls et al. 1995).

\section{Foods and supplemental nutrition}

The nutritional supplement was a commercially available product in regular use in our hospital (Resource, Novartis Nutrition) that contained $1046 \mathrm{~kJ}(250 \mathrm{kcal})$ energy, $13 \mathrm{~g}$ protein, $11 \mathrm{~g}$ fat, $52 \mathrm{~g}$ carbohydrate in $250 \mathrm{ml}$ by volume. The test meals were standardised in all studies. Identical quantities of foods were prepared by one of the investigators (A. B.) and the research dietitian. Subjects had unrestricted access to a variety of foods including tomato, ham, cheese, chicken, crackers, bread, butter, fruits, biscuits that were offered in separate portions and quantities were weighed before and after the meals to determine how much was consumed.

\section{Measurements}

Nutritional status. Each subject was assessed by the dietitian in the morning before the meal for nutritional status using the Subjective Global Assessment method (SGA; Detsky et al. 1987) and anthropometry (height, weight, triceps skinfold, mean arm circumference) to allow calculation of BMI, arm muscle area (AMA) and corrected arm muscle area (CAMA) using standard equations (Gurney \& Jelliffe, 1973; Friedman et al. 1985). Serum albumin levels were obtained from hospital records that were obtained within $4 \mathrm{~d}$ of the meal studies but not on the study day to avoid possible effects from venepuncture.

Appetite. The subjects completed five-point Likert scales on four occasions immediately before and $10 \mathrm{~min}$ after the premeal drinks and immediately before and after the meals to assess hunger, thirst, fullness, prospective consumption ('how much they could eat') and nausea (Rolls et al. 1995). Each scale had 0 representing the lowest level, e.g. not hungry/ thirsty/full/nauseated; 5 representing as hungry/thirsty/full/nauseated as possible; and scores 1-4 representing 'slightly', 'moderately', 'very', 'extremely' hungry/thirsty/full/nauseous. For prospective consumption, they were asked to rate 'how much could you eat?' and could respond nothing (0), slight amount (1), moderate amount (2), large amount (3), very large amount (4), extremely large amount (5) of food.

Food intake. The amount of foodstuffs consumed during each meal was determined and energy and macronutrient intakes were calculated using the Nuttab nutrient database (SERVE 3.95, SERVE Nutrition Management System, St Ives, New South Wales, Australia).

Statistics and calculations. Data were analysed using SPSS for Windows (version 10.0, SPSS Inc., Chicago). All subjects acted as their own control and Student's paired $t$-test was used to compare energy and macronutrient intakes. Energy regulatory responses were calculated in two ways as suggested by Rolls et al. (1995). The first method assessed the response to the energy content of the nutritional supplement. The percentage compensation at lunch for the supplement energy content was determined for each individual by subtracting lunch energy intake (kcal) after the supplement was consumed from the lunch intake in the control condition, dividing this difference by the supplement energy content $1046 \mathrm{~kJ}(250 \mathrm{kcal})$ and converting to a percentage. In this calculation, $100 \%$ (perfect) compensation would indicate that the subject consumed $1046 \mathrm{~kJ}$ less energy during the meal after the nutritional supplement. The second method calculated, as a percentage, the control meal energy relative to the total energy measured in the supplement condition (supplement plus meal intake) multiplied by 100. Again $100 \%$ indicates perfect compensation. For both calculations, values $<100 \%$ indicate undercompensation or overeating following the supplement. Student's $t$ tests were used to compare group means for unpaired normally distributed data. Likert scale 
scores were analysed using non-parametric tests and relevant pairs of data points compared included baseline scores for each condition (control $v$. supplement condition) and responses, e.g. difference scores after drinks and meals using Wilcoxon signed rank tests. Pearson correlation coefficients were obtained where data were normally distributed. Multiple linear regression was used with the stepwise procedure to examine correlates of energy compensation where univariate correlations existed. Correlates of energy intake and percentage energy compensation used all subjects combined given the similarity of responses between studies $\mathrm{A}$ and $\mathrm{B}$.

\section{Results}

Sample

Subject characteristics are provided in Table 1. Two subjects in each study group were rated as having suspected or mild-moderate malnutrition by SGA and the others were rated as well nourished. These four subjects plus another two in study B had AMA levels below the fifth percentile compared with normative data (Chumlea et al. 1988) and no subjects had severe wasting malnutrition as defined by CAMA.

\section{Subjective sensations}

There were no significant differences between the pre-meal scores on the Likert scales (hunger, prospective consumption, fullness, thirst) following the control or supplement drinks (Table 2). The subjects reported low levels of hunger, thirst and prospective consumption before the meals with all scores between 0 and 3 . Nausea was rarely reported and only transient or slight. The hunger, fullness and prospective consumption scores changed significantly but modestly $(P<0 \cdot 05)$ in the expected directions after the meals and there was no significant difference in post-meal or change scores between supplement and control conditions (Table 2).

\section{Energy and macronutrient intake}

The results of studies A and B were virtually identical and are presented in Table 3. There was no significant difference in mean total energy intakes during the buffet meals following the nutritional supplement drinks compared with non-caloric drinks,

Table 1. Characteristics of elderly women who participated in the meal studies

(Mean values and standard deviations)

\begin{tabular}{|c|c|c|c|c|}
\hline & \multicolumn{2}{|c|}{ Study A ( $n 7)$} & \multicolumn{2}{|c|}{ Study B ( $n 7)$} \\
\hline & Mean & SD & Mean & SD \\
\hline Age (years) & $77 \cdot 0$ & $6 \cdot 3$ & $81 \cdot 9$ & $7 \cdot 4$ \\
\hline Weight (kg) & $58 \cdot 6$ & $11 \cdot 9$ & $55 \cdot 4$ & $12 \cdot 5$ \\
\hline SGA status (A/B) & $5 / 2$ & & $5 / 2$ & \\
\hline BMI $\left(\mathrm{kg} / \mathrm{m}^{2}\right)$ & $22 \cdot 7$ & $2 \cdot 5$ & 22.5 & 3.7 \\
\hline Triceps skinfold (cm) & $15 \cdot 9$ & $2 \cdot 7$ & $13 \cdot 8$ & 3.5 \\
\hline Mid-arm circumference (cm) & $27 \cdot 7$ & $4 \cdot 1$ & $25 \cdot 3$ & $3 \cdot 8$ \\
\hline Arm muscle area $\left(\mathrm{cm}^{2}\right)$ & $41 \cdot 7$ & $12 \cdot 5$ & $36 \cdot 0$ & 14.4 \\
\hline MMSE & $25 \cdot 3$ & 3.9 & $24 \cdot 1$ & $3 \cdot 3$ \\
\hline Albumin (g) & 34.9 & $2 \cdot 9$ & 33.9 & 3.6 \\
\hline
\end{tabular}

SGA, Subjective Global Assessment; MMSE, mini-mental State Examination. whether the supplements were taken 90 or 30 min beforehand. As a result, in both studies A and B, a net gain in energy intake was seen when the energy content of the supplement drinks was added to the content of the meals. In both studies A and $\mathrm{B}$, this resulted in a net significant increase in energy that was virtually identical to the energy content of the nutritional supplement.

The calculated intakes of protein, carbohydrate and fat from the buffet meals were not significantly different following the nutritional supplement drinks compared with the control drinks whether the supplements were taken 90 or 30 min beforehand. As with energy intake, the estimated net increased intake of the macronutrients was very similar to the content of the supplement.

\section{Energy compensation}

There were no significant differences seen between the compensatory responses comparing the 90 and $30 \mathrm{~min}$ studies (unpaired $t$ tests; response to energy in supplement, $t 0 \cdot 46$; based on control: total intake, $t$ 0.88) (Table 4). The calculations for energy compensation indicated that on average, compensation for the premeal supplement was absent with the degree of overeating by the women close to the content of the supplement. When calculated in relation to the total energy intake after the supplement (meal plus supplement), this absence of energy compensation to the supplement meant that the elderly women increased their energy intake (overate) by about $40-50 \%$.

Correlates of hunger, prospective consumption, energy intake and compensation

Possible causes of low energy intake and impaired energy compensation were explored in relation to the nutritional indices (SGA, BMI, AMA, triceps skinfolds), subjective sensations, age and cognitive and depression scores.

Hunger and prospective consumption. No associations with pre-lunch hunger scores were found. Pre-lunch prospective consumption was significantly associated with triceps skinfold thickness as the nine subjects who scored 2 had thicker skinfolds than the five subjects who scored 1 on the scale (16.2 (SD 2.6) v. 11.7 (SD 2.1) cm, $t 3.011, P=0.012$ ).

Energy intake. There was a significant positive correlation between AMA and energy intakes during the control lunch ( $r 0.60, P=0.032)$. In addition pre-lunch prospective consumption scores were significantly associated with energy intakes; those who scored 2 on the scale consumed 1690 (SD 536) kJ whilst those who scored 1 consumed 862 (SD 352) $\mathrm{kJ}(t 3 \cdot 077, P=0 \cdot 01)$.

Energy compensation. Individual percentage compensatory energy responses in relation to the total energy intake (percentage control:total) were significantly associated with serum albumin levels $(r$ 0.59, $P=0.025)$, triceps skinfolds $(r$ 0.75, $P=0.003)$ and with energy intake during the control meal ( $r$ 0.73, $P=0.003)$. With stepwise linear multiple regression analysis examining these three variables, both triceps skinfold thickness and control energy intake remained significantly associated with percentage energy compensation (skinfold: $\beta$ 0.52, $t$ 2.63, $P=0.025$; control energy intake: $\beta \quad 0.46, t 2 \cdot 34, P=0.041$; see Fig. 1 for univariate correlations). 


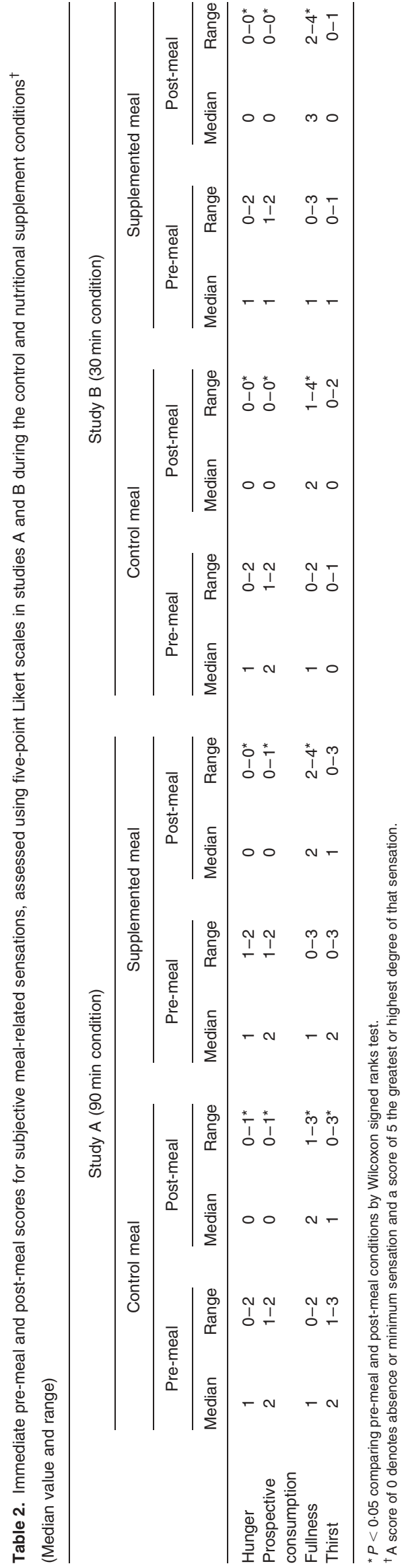

\section{Discussion}

Significant undernutrition is an important problem in elderly hospital patients that has grave implications for their survival and recovery (Bastow et al. 1983; Sullivan et al. 1995). Studies have examined the effect of pre-loads on meal regulation in healthy elderly subjects (Rolls et al. 1995; Zandstra et al. 2000) and in malnourished community-dwelling subjects (Sturm et al. 2003) but to our knowledge this is the first study examining this topic in hospitalised patients. The major findings of this study carried out in elderly hospitalised women recovering from major lower limb fractures were as follows. (1) The women demonstrated low ratings of hunger and readiness to eat and consumed fairly small quantities of energy (food) during an ad libitum luncheon meal. (2) There was a complete absence of suppression of food intake after a liquid oral nutritional supplement given as a pre-load whether given 30 or $90 \mathrm{~min}$ before the meal. (3) There were significant associations between assessments of nutritional status (skinfold thickness, AMA) and appetite ratings, energy intake and the deficit in energy compensation, suggesting that these abnormal compensatory responses are related to longer-term (under)nutrition.

The midday meal generally provides around $33 \%$ of the daily energy intake of older Britons (Schlettwein-Gsell et al. 1999). Extrapolating this estimate to our cases (predominantly of British origin) who consumed an average $1393 \mathrm{~kJ}$ (333 kcal) during the lunch (range 372-2494 kJ) indicates that these women probably had low daily energy intakes, that would be considered sub-optimal for rehabilitation and good health. This is consistent with previous surveys, which have shown that patients recovering from hip fracture often have inadequate energy intakes (Stableforth, 1986; Jallut et al. 1990) and continue to lose weight for many weeks (Bruce et al. 2003).

We found that energy intake correlated with triceps skinfold thicknesses and with AMA indicating that the subjects with evidence of loss of body fat stores and sarcopaenia had the lowest energy intakes during the meals. In addition, those with reduced appetite as measured by the readiness-to-eat scale had lower skinfold thicknesses and lower energy consumption. Thus those with poorer appetites were both thinner and consumed lower energy intakes consistent with the hypothesis that it was chronic anorexia that led to both pre-fracture undernutrition and poor energy intakes during the recovery phase.

Substantial abnormalities in the adjustment of energy intake were seen as the subjects failed to reduce their intake of food after drinking a pre-meal supplement even when given only $30 \mathrm{~min}$ before the meal, a rigorous test of energy compensation (Rolls et al. 1995). Other studies have reported that energy compensation after pre-meals in healthy older subjects is generally normal (Zandstra et al. 2000; Sturm et al. 2003) or slightly impaired (Rolls et al. 1995) compared to younger subjects. Sturm et al. (2003) recently reported a similar degree of failure of adjustment of food intake after a pre-meal in severely malnourished elderly women (BMI $16.9 \mathrm{~kg} / \mathrm{m}^{2}$ ). The reasons for the lack of energy compensation cannot be deduced from this study. We have no control data from non-hospitalised subjects or hospitalised patients without fracture and so are unable to determine whether the nature or extent of illness response are important causative factors. However, energy compensation correlated independently with both triceps skinfold thicknesses and energy intake during the control meals, implicating chronic undernutrition (as assessed by low 
Table 4. Percentage energy compensation due to nutritional supplements in elderly hospitalised women

(Mean values with their standard deviations)

\begin{tabular}{|c|c|c|c|c|}
\hline & \multicolumn{4}{|c|}{$\%$ Energy compensation } \\
\hline & \multicolumn{2}{|c|}{$\begin{array}{l}\text { Response to energy content of } \\
\text { nutritional supplement }\end{array}$} & \multicolumn{2}{|c|}{$\begin{array}{l}\text { Based on control: } \\
\text { total intake }\end{array}$} \\
\hline & Mean & SD & Mean & SD \\
\hline Study A & $11 \cdot 8$ & $51 \cdot 7$ & $62 \cdot 8$ & $19 \cdot 4$ \\
\hline Study B & 0.8 & $45 \cdot 0$ & $53 \cdot 6$ & $19 \cdot 7$ \\
\hline
\end{tabular}

Calculation: (baseline - condition intake)/energy in supplement; $100 \%$ indicates perfect compensation.

${ }^{*}$ Calculation: (baseline/total (meal + supplement) intake).
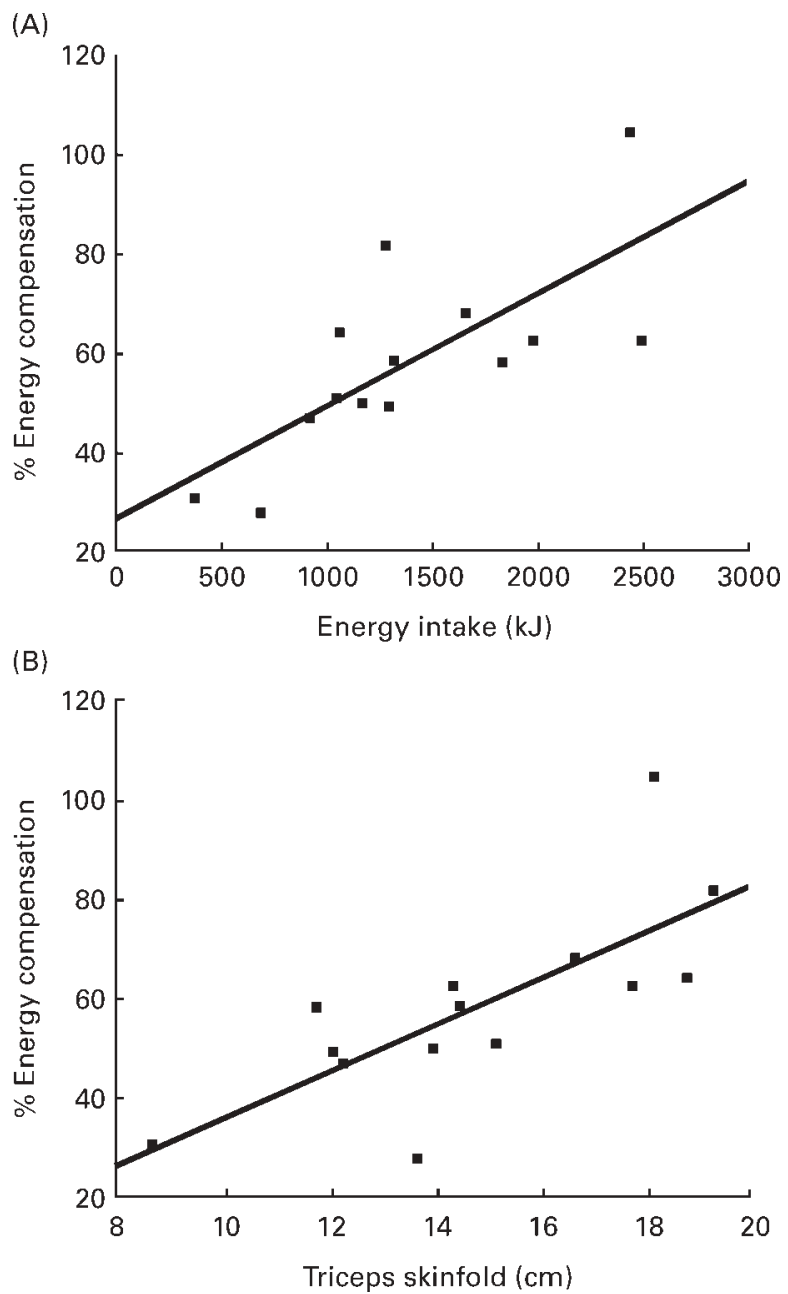

Fig. 1. Univariate correlations between percentage energy compensation in relation to total energy intake (see text for calculation) and energy intake during control meals (A) and triceps skinfold thickness (B) in fourteen elderly hospitalised women.

skinfold) and anorexia (as assessed by low food intake) as important determinants of this phenomenon. This conclusion is similar to that of Sturm et al. (2003) although the average BMI of our hospitalised women $\left(22.5 \mathrm{~kg} / \mathrm{m}^{2}\right)$ who failed to compensate was close to their well-nourished women (BMI $23.7 \mathrm{~kg} / \mathrm{m}^{2}$ ) who compensated normally (Sturm et al. 2003). These differences may suggest that other factors contribute to the lack of energy compensation in 
hospitalised patients, possibly related to the metabolic response to injury (Paillaud et al. 2000) and appetite-suppressing cytokines (Morley, 2001).

In the present study, because of absence of energy compensation and low baseline energy and macronutrient intakes, the standard nutritional supplement we used increased lunch-time energy intake $60-80 \%$ and protein intake $60 \%$ over baseline levels. Our findings appear to show that the time period when liquid dietary supplements can be given without compromising meal intakes is closer to meal times than previously recommended (Wilson et al. 2002), at least in the hospital setting.

The study has several additional important limitations. The responses on the Likert scales were generally low in these subjects with the tests having limited discriminatory power. In general, these subjects appeared to have low motivation to eat during the experiments and we need to urge caution about conclusions based on associations with these variables. Other limitations are related to the small sample size, lack of blinding of study arms and heterogeneity of nutritional status of the subjects. Another important limitation of the present study is that we have studied patients at a single time point and it is not known whether our findings represent a temporary or prolonged phenomenon. It would be important to determine whether the apparently positive impact on energy intakes provided by nutritional supplements close to regular mealtimes in hospitalised patients is maintained in longer-term studies.

\section{Acknowledgements}

Dr Boudville was responsible for carrying out the study, data analysis and manuscript preparation. Associate Professor Bruce was responsible for the study design and assisted with data analysis and manuscript writing. Neither author has conflicts of interest to declare based on financial or personal relationships with sponsors or companies. We wish to acknowledge the contribution of Alison Jarman, Tanya Collins and Nadia Ward who assisted with meal preparation and nutrient analysis. This project was funded by a grant from the Medical Research Foundation of Fremantle Hospital.

\section{References}

Avenell A \& Handoll HHG (2001) Nutritional supplementation for hip fracture aftercare in the elderly (Cochrane review). In The Cochrane Library, issue 4. Oxford: Update Software.

Banerjee AK, Brocklehurst JC, Wainwright H \& Swindell R (1978) Nutritional status of long stay geriatric inpatients: effects of a food supplement (Complan). Age Ageing 7, 237-243.

Bastow MD, Rawlings J \& Allison SP (1983) Benefits of supplementary tube feeding after fractured neck of femur: a randomised controlled trial. BMJ 287, 1589-1592.

Bruce D, Laurance I, McGuiness M, Ridley M \& Goldswain P (2003) Nutritional supplements after hip fracture: poor compliance limits effectiveness. Clin Nutr 22, 497-500.

Chumlea WC, Roche AF \& Mukherjee D (1988) Nutritional Assessment in the Elderly Through Anthropometry. Monograph no. P527. Columbus, USA: Ross Laboratories.
Detsky AS, McLaughlin JR, Baker JP, et al. (1987) What is subjective global assessment of nutritional status? J Parenter Enteral Nutr 11, $8-13$.

Fiatarone MA, O’Neill EF, Ryan ND, et al. (1994) Exercise training and nutritional supplementation for physical frailty in very elderly people. N Engl J Med 330, 1769-1820.

Friedman PJ, Campbell AJ \& Caradoc-Davies TH (1985) Prospective trial of a new diagnostic criterion for severe wasting malnutrition in the elderly. Age Ageing 14, 149-154.

Garner DM \& Garfinkel PE (1979) The Eating Attitudes Test: an index of the symptoms of anorexia nervosa. Psychiatr Med 9, 273-280.

Gurney JM \& Jelliffe DB (1973) Arm anthropometry in nutritional assessment: nomogram for rapid calculation of muscle circumference and cross-sectional muscle over fat areas. Am J Clin Nutr 26, 912-915.

Jallut D, Tappy L, Kohut M, et al. (1990) Energy balance in elderly patients after surgery for a femoral neck fracture. $J$ Parenter Enteral Nutr 14, 563-568.

Kayser-Jones J, Schell ES, Porter C, et al. (1998) A prospective study of the use of liquid dietary supplements in nursing homes. $J$ Am Geriatr Soc 46, 1378-1386.

McCrea D, Arnold E, Marchevsky D \& Kaufman BM (1994) The prevalence of depression in geriatric medical outpatients. Age Ageing 23, $465-467$.

Morley JE (2001) Decreased food intake with aging. J Gerontol 56A, $81-89$.

Morley JE (1997) Anorexia of aging: physiologic and pathologic. Am J Clin Nutr 66, 760-773.

Paillaud E, Bories PN, Le Parco JC \& Campillo B (2000) Nutritional status and energy expenditure in elderly patients with recent hip fracture during a 2-month follow-up. Br J Nutr 83, 97-103.

Potter J, Langhorne P \& Roberts M (1998) Routine protein energy supplementation in adults: systematic review. BMJ 31, 495-501.

Rolls BJ, Dimeo KA \& Shide DJ (1995) Age-related impairments in the regulation of food intake. Am J Clin Nutr 62, 923-931.

Schlettwein-Gsell D, DeCarli B \& De Groot L (1999) Meal patterns in the SENECA study of nutrition and the elderly in Europe: assessment method and preliminary results of the role of the midday meal. Appetite 23, 15-22.

Stableforth PG (1986) Supplement feeds and nitrogen and calorie balance following femoral neck fracture. British Journal of Surgery 73, $651-655$.

Stunkard AJ \& Messick S (1985) The three factor eating questionnaire to measure dietary restraint, disinhibition and hunger. J Psychosom Res 29, 71-83.

Sturm K, Macintosh CG, Parker BA, Wishart J, Horowitz M \& Chapman IM (2003) Appetite, food intake, and plasma concentrations of cholecystokinin, Ghrelin, and other gastrointestinal hormones in undernourished older women and well-nourished young and older women. $J$ Clin Endocrinol Metab 88, 3747-3755.

Sullivan DH, Walls RC \& Bopp MM (1995) Protein-energy malnutrition and the risk of mortality within one year of hospital discharge: a follow-up study. J Am Geriatr Soc 43, 507-512.

Tucker H \& Miguel S (1996) Cost containment through nutritional intervention. Nutr Rev 54, 111-121.

Wilson MMG, Purushothaman R \& Morley JE (2002) Effect of liquid dietary supplements on energy intake in the elderly. Am J Clin Nutr 75, 944-947.

Zandstra EH, Mathey M-FAM, De Graaf C \& Van Staveren WA (2000) Short-term regulation of food intake in children, young adults and the elderly. Eur J Clin Nutr 54, 239-246. 